\title{
The Pathogenic Involvement of Neutrophils in Acute Respiratory Distress Syndrome and Transfusion- Related Acute Lung Injury
}

\author{
Johan Rebetz John W. Semple Rick Kapur \\ Division of Hematology and Transfusion Medicine, Lund University, Lund, Sweden
}

\section{Keywords}

Acute respiratory distress syndrome $\cdot$ ARDS $\cdot$ Neutrophil . TRALI - Transfusion-related acute lung injury

\section{Summary}

The acute respiratory distress syndrome (ARDS) is a serious and common complication of multiple medical and surgical interventions, with sepsis, pneumonia, and aspiration of gastric contents being common risk factors. ARDS develops within 1 week of a known clinical insult or presents with new/worsening respiratory symptoms if the clinical insult is unknown. Approximately $40 \%$ of the ARDS cases have a fatal outcome. Transfusion-related acute lung injury (TRALI), on the other hand, is characterized by the occurrence of respiratory distress and acute lung injury, which presents within $6 \mathrm{~h}$ after administration of a blood transfusion. In contrast to ARDS, acute lung injury in TRALI is not attributable to another risk factor for acute lung injury. 'Possible TRALI', however, may have a clear temporal relationship to an alternative risk factor for acute lung injury. Risk factors for TRALI include chronic alcohol abuse and systemic inflammation. TRALI is the leading cause of transfusionrelated fatalities. There are no specific therapies available for ARDS or TRALI as both have a complex and incompletely understood pathogenesis. Neutrophils (polymorphonuclear leukocytes; PMNs) have been suggested to be key effector cells in the pathogenesis of both syndromes. In the present paper, we summarize the literature with regard to PMN involvement in the pathogenesis of both ARDS and TRALI based on both human data as well as on animal models. The evidence generally supports a strong role for PMNs in both ARDS and TRALI. More research is required to shed light on the pathogenesis of these respiratory syndromes and to more thoroughly establish the nature of the PMN involvement, especially considering the heterogeneous etiologies of ARDS.

(c) 2018 S. Karger GmbH, Freiburg

\section{Introduction}

Acute respiratory distress syndrome (ARDS), first described in 1967 [1], is characterized by acute inflammatory lung injury which increases lung microvascular permeability, resulting in hypoxic respiratory distress. Clinically, ARDS presents with respiratory signs and symptoms (increased respiratory rate, pulmonary crackles upon auscultation), and hypoxia (central cyanosis). The diagnosis of ARDS (Berlin definition of 2012) [2] is based on the presence of the following criteria:

1) Acute onset: within 1 week of a known clinical insult or new/ worsening respiratory symptoms if the clinical insult is unknown.

2) Pulmonary edema: bilateral lung field opacities on chest X-ray which is not exclusively hydrostatic (so not entirely related to cardiac failure or volume overload).

3) Hypoxia: ratio of arterial oxygen tension to inspired oxygen concentration $<40 \mathrm{kPa}$. Risk factors for ARDS include sepsis, pneumonia and aspiration of gastric contents [3].

Around $40 \%$ of ARDS cases are fatal [4], and in the remaining cases survivors may suffer from long-term sequelae. No specific therapies are available for ARDS; however, good supportive management reduces the damage and improves the outcome [3].

Transfusion-related acute lung injury (TRALI) is characterized by the onset of acute respiratory distress within $6 \mathrm{~h}$ following blood

\section{KARGER}

(c) 2018 S. Karger GmbH, Freiburg 
transfusions. It is the leading cause of transfusion-related fatalities [5]. TRALI is diagnosed according to the Canadian Consensus Conference Panel TRALI [6]:

1) Acute lung injury: Acute onset. Hypoxemia: $\mathrm{SpO} 2<90 \%$ or $\mathrm{PaO} 2 / \mathrm{FiO} 2<300 \mathrm{~mm} \mathrm{Hg}$ on room air, or other clinical evidence of hypoxemia. Bilateral infiltrates on frontal chest X-ray. No evidence of left atrial hypertension such as circulatory overload.

2) No preexisting acute lung injury before transfusion.

3) Occurs during or within $6 \mathrm{~h}$ of transfusion.

4) No temporal relationship to an alternative risk factor for acute lung injury (including pneumonia, sepsis, aspiration, multiple trauma, acute pancreatitis).

The term 'Possible TRALI' was defined as acute lung injury, with no preexisting acute lung injury before transfusion, occurring during or within $6 \mathrm{~h}$ after transfusion, but with a clear temporal relationship to an alternative risk factor for acute lung injury [6]. Apart from supportive measures such as oxygen and ventilation, no specific therapy is available for TRALI. Generally, a two-hit model is assumed to underlie the disease. The first hit represents patient predisposing factors, such as inflammation. The second hit is due to human leukocyte antigen (HLA) class I/II or human neutrophil antigen (HNA) antibodies or donor biological response modifiers (bioactive lipids, mitochondrial damage-associated molecular patterns, extracellular vesicles, or aged cellular blood products) which are present in the donor blood [7]. First-hit risk factors for TRALI include chronic alcohol abuse, liver surgery, smoking, shock, higher peak airway pressure while undergoing mechanical ventilation, and positive intravascular fluid balance [7]. More specifically, systemic inflammation is a major risk factor for TRALI and is characterized by elevated recipient interleukin 6 (IL-6) [8] and IL-8 levels [8-10] as well as by increased C-reactive protein (CRP) levels [11, 12]. Additionally, a dysregulation of CD4+ T regulatory cells or dendritic cells has been described as first-hit risk factors using murine models of TRALI [13]. Furthermore, decreased IL-10 levels were found in both murine models of TRALI [13] as well as in human TRALI patients [14]. Despite a similar clinical presentation, it is important to note that the underlying pathophysiological mechanisms are different in ARDS and TRALI. In the present paper, we will address the role of polymorphonuclear leukocytes (PMNs) in the pathogenesis of both ARDS and TRALI.

\section{Neutrophils as Immune Effector Cells}

Neutrophils (PMNs) are derived from hematopoietic stem cells in the bone marrow and are approximately $12-14 \mu \mathrm{m}$ in diameter with a multilobed nucleus and a granular cytoplasm. They are the most common type of granulocytes and constitute more than half of all circulating leukocytes. In healthy adults, around 36\% of all PMNs are residing in the circulation, and of the total number of PMNs around 28\%, both circulating and non-circulating, are suggested to be present in the pulmonary pool $[15,16]$. The number of PMNs in the pulmonary pool is subject to change upon systemic inflammatory conditions. During inflammation, PMNs are the first responders and recruited in large numbers to the inflammatory microenvironment by the accumulation of lipid mediators, cytokines, and chemokines as well as changes to the vascular endothelium $[17,18]$. The migration of PMNs towards the inflamed tissue is a complex interplay between the PMN and the adhesive molecules on the vascular endothelium. This multi-step process involves PMN-endothelial tethering, rolling, adhesion, crawling, and PMN-transendothelial migration [19]. The early tethering stage involves cell adhesion molecules, e.g. selectins, on the endothelial cells and their ligands such as P-selectin glycoprotein ligand 1 (PSGL1) on PMNs [20-22]. During the subsequent rolling step, chemokine receptors are engaged, and neutrophils migrate along a gradient of chemotactic factors immobilized by binding to negatively charged glycosaminoglycans (GAGs) and heparan sulfate proteoglycans (HSPGs) on the luminal surface of endothelial cells [23]. PMN rolling and the engagement of chemokine receptors induces conformational changes in cell surface $\beta 2$-integrins, which are transmembrane receptors that facilitate cell-extracellular matrix adhesion, allowing PMNs to bind with higher affinity to their ligands leading to a firm adhesion $[19,24,25]$. During this process PMNs self-organize with a leading pseudopod and a trailing uropod, which subsequently leads to crawling, a process which is distinct from firm adhesion. The PMN crawling occurs unrelated to the direction of the blood flow and aims to find endothelial junctions for initiation of transmigration. PMNs may also facilitate transendothelial migration by production of reactive oxygen species (ROS) [26-29]. Transendothelial-migration is a critical step for the PMN to reach the site of inflammation and requires an activated state of the endothelium [30,31]. At the site of inflammation, PMNs can elicit a number of immunological responses towards pathogens. These immune responses are tightly regulated in order to facilitate elimination of invading pathogens without inducing detrimental effects to host tissues. Specific activation/deactivation of PMN cell surface immune receptors by a wide range of extracellular signals regulates their effector functions. Bacteria can be engulfed and taken up by PMNs and degraded intracellularly in a process called phagocytosis $[32,33]$. Intracellular vesicles and granules containing ROS and antibacterial proteins fuse with the phagosome creating a lysosome where the pathogen is degraded [34]. Phagocytosis is mediated by antibodies or complement factors that bind to the surface of pathogens that are recognized by immune receptors on PMNs. These include $\mathrm{Fc} \gamma$ receptors which recognize the Fc-tail of the immunoglobulin $\mathrm{G}(\mathrm{IgG})$ which bounds pathogens via the IgG-Fab part [35-37]. Complement is activated by antibodies bound to pathogens, primarily IgG and IgM, and subsequently cleaved complement products are deposited on pathogens and recognized by complement receptors (CRs) on PMNs [38]. PMN granules with all their toxic components can also can also be released into the extracellular environment [34, 39]. PMNs may also respond to pathogens by releasing so-called neutrophil extracellular traps (NETs), which are formed by release of granule proteins and chromatin which together form extracellular fibers that trap and kill extracellular pathogens [40]. 
Apart from the beneficial roles of PMNs in recruitment to sites of inflammation, recognition and phagocytosis of pathogens, production of ROS and secretion of NETs, PMNs may also have damaging functions. Secretion of NETs, for instance, may also cause damage to the host, e.g. by impairing wound healing in diabetes [41] or through impairment of lung mechanics in ventilator-induced lung injury [42]. PMNs have also been implicated in autoimmune diseases, including Wegener's granulomatosis, microscopic polyangiitis, Churg-Strauss syndrome, renal vasculitis; diseases in which autoantibodies are produced which bind PMN antigens triggering cellular activation [43]. Additionally, PMNs may exhibit a pathogenic role in allergic diseases including anaphylaxis [44] and pulmonary allergic inflammation in chronic mycoplasma infection [45]. Furthermore, PMNs are implicated in the pathophysiology of inflammatory bowel disease, both Crohn's disease and ulcerative colitis, with the degree of PMN infiltration in the intestinal wall being correlated with the clinical disease severity [46]. In the current paper, we will focus on the pathogenic contribution of PMNs in a pulmonary setting of ARDS and TRALI.

\section{Neutrophil Involvement in ARDS}

The pathogenesis of ARDS has been studied extensively over the years. Similar to TRALI, the disease mechanisms are incompletely understood, and specific therapies are lacking. There are few studies based on histopathological data from ARDS patients and multiple studies based on ARDS patient-derived data and animal models of ARDS. Collectively, they generally support a key role for PMNs in the pathogenesis of ARDS (table 1). Interestingly, however, there are also studies reporting the occurrence of ARDS in neutropenic patients, highlighting the complexity of the ARDS pathogenesis (table 1). The evidence for PMN involvement in ARDS is summarized in table 1.

\section{Neutrophil Involvement in TRALI}

PMNs are generally considered to be key effector cells in TRALI. Pulmonary PMN infiltration has been described to occur in multiple animal models of TRALI [11, 13, 47-57]. Additionally, the abundance of PMNs has been observed in pulmonary tissue of TRALI patients upon autopsy [58, 59]. PMNs are major producers of ROS, and ROS production has been suggested to damage the endothelium in murine antibody-mediated TRALI models $[53,60]$ and in human pulmonary microvascular endothelial cells in vitro [61]. Importantly, wild-type mice depleted of their PMNs or C57BL/6 ROS knockout mice (gp91phox knockout mice) were both completely protected from severe TRALI, underlining the critical involvement of PMNs and ROS in inducing antibody-mediated TRALI [13]. Two studies have reported the occurrence of NETs in TRALI, indicating PMNs to be involved in TRALI. One study observed NETs in the lungs and plasma of TRALI patients and demonstrated that platelets were the trigger for NET forma- tion using a murine model of anti-major histocompatibility complex (MHC) class I antibody-mediated TRALI model [49]. Another study reported that NET biomarkers were present in the serum of TRALI patients as well as in the lungs of mice which underwent anti-MHC class I antibody-mediated TRALI [62]. In a setting of non-antibody-mediated TRALI, lipids from stored blood were also shown to cause PMN-mediated endothelial cell damage using an in vitro TRALI model, in which human pulmonary microvascular endothelial cells were activated with lipopolysaccharide and co-cultured with PMNs with addition of lysoPC as the second hit of transfusion [63]. This PMN-dependent endothelial cell damage also occurred when adding sCD40L instead of lysoPC [64]. Also other studies found PMN-mediated endothelial cell damage using an in vitro TRALI model in a setting of both non-antibody mediated TRALI [65] and antibody-mediated TRALI $[61,66,67]$. Furthermore, PMNs were found to interact with von Willebrand factor via choline transporter-like protein-2 (CTL-2), which allowed anti-HNA-3a antibody to induce signal transduction via CD11b/ CD18, leading to PMN activation and agglutination [54]. This mechanism may aggravate endothelial cell damage in anti-HNA $3 \mathrm{a}$ antibody-mediated TRALI.

Using a murine model of anti-HNA-3a antibody-mediated TRALI, it was found that PMN depletion alleviated the disease severity; however, the authors observed that the disease still occurred [53]. Another study, using a murine model of anti-MHC class I antibody-mediated TRALI, has suggested that TRALI is not dependent on PMNs but rather on complement component C5a, with C5-deficient mice being protected from antibody-mediated TRALI while infusion of these deficient mice with complementcontaining plasma restored the lung injury [60]. This study also found anti-MHC class I antibody-mediated TRALI to be at least partially independent of $\mathrm{Fc} \gamma$ receptors. In contrast, however, an earlier study did find PMNs to be important effector cells in TRALI and reported the occurrence of TRALI in C5aR-deficient BALB/c mice $2 \mathrm{~h}$ after injection of the same anti-MHC class I antibody [47]. Moreover, they found PMN Fc $\gamma$ Rs to be critically involved as adoptive transfer of wild-type PMNs into TRALI-resistant BALB/c $\mathrm{F} c \gamma \mathrm{R}$ knockout mice restored the acute lung injury upon challenge with anti-MHC class I antibody [47]. Differences between these studies may be due to the timing of experimental endpoints after antibody injection which was $30 \mathrm{~min}$ in one study [60] versus $2 \mathrm{~h}$ in the other study [47]. Furthermore, TRALI has been described in a neutropenic patient [68], arguing against a pathogenic role for PMNs in TRALI. In addition, another study reported two TRALI patients which did not demonstrate PMN influx into the alveolar airspace upon histological analysis of lung tissue sections [69]. The evidence for PMN involvement in TRALI is summarized in table 2.

\section{Discussion}

The evidence for PMN involvement, as summarized in table 1 (for ARDS) and table 2 (for TRALI), indicates a strong involvement for PMNs in the pathogenesis of both ARDS and TRALI. 
Table 1. Evidence for and against PMN involvement in ARDS, based on both animal models as well as human data

Evidence for PMN involvement in ARDS

A) Histopathological PMN evidence from ARDS patients:

1) Pathologic finding in lungs of 9 ARDS patients included interstitial and alveolar edema with accumulation of alveolar PMNs, macrophages and erythrocytes[75]

2) Case report of 1 ARDS patient who demonstrated microvascular granulocyte aggregation and lung edema upon lung histological analysis [76]

3) Pathological finding based on 59 ARDS patients showed diffuse alveolar damage with PMNs, macrophages, erythrocytes, hyaline membranes and protein-rich edema fluid in the alveolar spaces [77]
Evidence against PMN involvement in ARDS

A) Occurrence of ARDS in neutropenic patients:

1) 11 neutropenic patients with ARDS, without pulmonary PMN filtration [78]

2) 4 neutropenic with ARDS [79]

3) Development of ARDS in 22 children with neutropenia, no signs of pulmonary PMN infiltration [80]

4) ARDS development in 5 neutropenic patients after bone marrow transplantation for chronic myeloid leukemia [81]

5) 17 neutropenic patients with septic ARDS, deactivation of alveolar macrophages is suggested in these patients [82]

6) 12 neutropenic cancer patients with septic-related ARDS, deactivation of monocytes is suggested in these patients [83]

7) 7 episodes of ARDS occurring in leukemic patients with longstanding (average 11 days) and severe neutropenia [84]

8) 5 neutropenic patients with ARDS [85]

9) Histologic examination of the lungs from two neutropenic patients with ARDS demonstrated the absence of PMNs [86]

B) ARDS patient (-derived) PMN data:

1) Natural inhibitor of PMN function correlates with decreased PMN mediated ARDS [87]

2) Retention of ex-vivo primed PMNs in ARDS patients [88]

3) Lung PMNs in ARDS correlate with abnormalities of gas exchange and lung protein permeability, and neutrophil products capable of mediating lung injury can be recovered from the lungs of these patients [89]

4) Increased levels of lactoferrin, a specific granule protein of PMNs, in ARDS patients, also in relation to circulating PMN numbers [90]

5) High concentration of peptide released by macrophages caused PMN to secrete azurophilic granule enzymes in ARDS patients [91]

6) Increased pulmonary levels of PMN-derived S100A12 in patients with ARDS [92]

7) Increased expression of PMN-related genes in patients with early sepsis-induced ARDS [93]

8) Increased PMN-ROS activation in post-traumatic ARDS patients [94]

9) Alteration of chemotactic and secretory processes in PMNs derived from ARDS patients [95]

10) Granulocyte adherence in pulmonary and systemic arterial blood samples from ARDS patients [96]

11) Increased IL-8-related PMN elastase complexes correlate to severity in mechanically ventilated and large sepsis-related ARDS patients [97]

12) Lower ADCC and bacterial killing ability of peripheral blood and alveolar PMNs from ARDS patients [98]

13) Increased PMN elastase activity in alveolar fluid from ARDS patients [99]

14) Ex-vivo stimulation of PMNs from ARDS patient demonstrate hyperresponsiveness and correlate with elevated plasma levels of TNF-a [100]

15) Low proportion of apoptotic PMNs in BAL of ARDS patients [101]

16) Inhibition of PMN apoptosis by BAL fluid from patients on days 1 and 3 of ARDS (not at later stages) [102]

17) Lower peripheral blood-derived $P M N$ apoptosis in sepsis-induced ARDS [103]

18) PMNs from ARDS patients demonstrate a varying degree of activation [104]

19) Abnormal PMN-lung interaction in ARDS patients as observed by increased pulmonary PMN localization in ARDS using scintigraphy [105]

20) Increased ROS-releasing and metabolic activity of PMNs derived from ARDS patients [106]
B) ARDS patient (-derived) PMN data:

1) In clinical trials patients with severe pneumonia received granulocyte colony-stimulating factor (Filgrastim), which increased the number of circulating PMNs 3-fold, but this did not increase the incidence or severity of lung injury [119]

2) Massive oxidative stress observed through plasma analysis from ARDS patients, however, ROS generation from PMNs was found be normal on day 0 and decreased to day 6 in ARDS patients [120] 
Table 1. Continued

\begin{tabular}{|c|c|}
\hline Evidence for PMN involvement in ARDS & Evidence against PMN involvement in ARDS \\
\hline \multicolumn{2}{|l|}{$\begin{array}{l}\text { 21) Impaired function of lung and blood PMNs of ARDS patients (im- } \\
\text { paired superoxide anion and hydrogen peroxide production and im- } \\
\text { paired microbicidal activity of lung PMNs and reduced migration of } \\
\text { alveolar PMNs) [107] }\end{array}$} \\
\hline \multicolumn{2}{|l|}{$\begin{array}{l}\text { 22) IPulmonary PMN accumulation (111In-labeled PMNs) in } 3 \text { sepsis- } \\
\text { related ARDS patients [108] }\end{array}$} \\
\hline \multicolumn{2}{|l|}{$\begin{array}{l}\text { 23) IPMN elastase-releasing factors described in BAL from ARDS patients } \\
\text { [109] }\end{array}$} \\
\hline \multicolumn{2}{|l|}{$\begin{array}{l}\text { 24) Reduced bactericidal activity (impaired phagocytosis and killing) of } \\
\text { blood PMNs from ARDS patients [110] }\end{array}$} \\
\hline \multicolumn{2}{|l|}{$\begin{array}{l}\text { 25) NETs were observed in bronchial aspirates from gastric-aspiration- } \\
\text { induced ARDS patients [111] }\end{array}$} \\
\hline \multicolumn{2}{|l|}{$\begin{array}{l}\text { 26) Presence of NETs in human patients with pneumonia and sepsis- } \\
\text { related ARDS. Increased plasma NETs were associated with ARDS } \\
\text { severity and mortality, and lower plasma DNase I levels were } \\
\text { associated with the onset of sepsis-induced ARDS [112] }\end{array}$} \\
\hline \multicolumn{2}{|l|}{$\begin{array}{l}\text { 27) G-CSF and IL-8 but not GM-CSF correlate with severity of increased } \\
\text { pulmonary PMNs in BAL fluid from ARDS patients [113] }\end{array}$} \\
\hline \multicolumn{2}{|l|}{ 28) Increased presence of PMNs in BALs from sepsis and trauma-related } \\
\hline \multicolumn{2}{|l|}{ 29) Increased blood PMN-elastase levels in ARDS patients [115] } \\
\hline \multicolumn{2}{|l|}{$\begin{array}{l}\text { 30) Leukocyte and PMN-derived microparticles were found to be elevated } \\
\text { in BALs from ARDS patients [116] }\end{array}$} \\
\hline \multicolumn{2}{|l|}{ 31) Increased numbers of PMNs in BALs from ARDS patients, with } \\
\hline PMNs displaying adherence-promoting activity [117] & \\
\hline \multicolumn{2}{|l|}{ 32) High levels of PMNs in BALs from patients with early ARDS [118] } \\
\hline \multirow{9}{*}{\multicolumn{2}{|c|}{$\begin{array}{l}\text { C) Pulmonary PMN infiltration in animal models of ARDS: } \\
\text { 1) Endotoxemia rabbit ARDS model [121] } \\
\text { 2) Lung lavage rat ARDS model [122] } \\
\text { 3) Malaria-ARDS mouse model [123] } \\
\text { 4) Endotoxemia pig model, with protection by PMN depletion [124] } \\
\text { 5) H9N2 virus induced murine ARDS model [125] } \\
\text { 6) Acid-aspiration induced rat ARDS model [126] } \\
\text { 7) Murine lipopolysaccharide-induced endotoxemia model [127] } \\
\text { 8) Sepsis-induced primate ARDS model [128] }\end{array}$}} \\
\hline & \\
\hline & \\
\hline & \\
\hline & \\
\hline & \\
\hline & \\
\hline & \\
\hline & \\
\hline \multicolumn{2}{|l|}{ D) Increased PMN responses in animal models of ARDS: } \\
\hline \multicolumn{2}{|l|}{ 1) Increased ROS production in rat endotoxemia ARDS model [130] } \\
\hline \multicolumn{2}{|l|}{$\begin{array}{l}\text { 2) Evidence for PMN-ROS activity in rat model of IL-1-instilled ARDS } \\
\text { [131] }\end{array}$} \\
\hline \multicolumn{2}{|l|}{ 3) NETs contribute to murine acid-aspiration-induced ARDS [111] } \\
\hline $\begin{array}{l}\text { 4) Excessive PMNs and pulmonary NET formation in a murine model of } \\
\text { influenza-induced ARDS [132] }\end{array}$ & \\
\hline
\end{tabular}

There were, however, several reports describing the occurrence of ARDS in neutropenic patients and also few studies indicating a lack of PMN involvement in human TRALI patients.

Despite a strong evidence for PMN involvement in ARDS, ARDS occurred in neutropenic patients, and not all studies found the same type of alteration in PMN function in blood or bronchoalveolar lavage (BAL) fluid from ARDS patients. This may be due to the heterogeneous etiologies of ARDS, which is evident from data obtained in humans as well as from the use of different animal models for ARDS. This complicates the pathogenic analysis of ARDS, making it also unclear if there may be a final common pathway for acute lung injury in different types of ARDS. Moreover, a lot of data is derived from BAL fluids from ARDS patients.
Analysis of PMNs and mediators from BAL fluids may not necessarily reflect or reveal the essential interactions between pathogenic factors and the pulmonary endothelium which occur during the onset of pulmonary edema and ARDS. Future human studies should continue to focus on the mechanisms of the acute lung injury by investigating blood cells, circulating plasma markers, and BAL fluids from ARDS patients, but clearly stratified to their specific type of ARDS.

TRALI was described in a neutropenic patient [68]. However, the authors hypothesize that donor anti-HLA antibodies may have bound directly to the endothelium and facilitated entrapment and activation of PMNs despite the low PMN counts [68]. Additionally, they suggest that the short duration of the clinical of episode of 
Table 2. Evidence for and against PMN involvement in TRALI, based on both animal models (antibody-and non-antibody mediated) as well as human data. Regarding experimental models of TRALI, items B1, B2, B4 and E2 refer to non-antibody mediated TRALI

\begin{tabular}{|c|c|}
\hline Evidence for PMN involvement in TRALI & Evidence against PMN involvement in TRALI \\
\hline A) PMNs present in lung tissue of TRALI patients upon autopsy [58,59] & A) Occurrence of TRALI in a neutropenic patient [68] \\
\hline $\begin{array}{l}\text { B) PMN-mediated endothelial cell damage using in vitro human TRALI } \\
\text { models: } \\
\text { 1) Second hit lyso-PC [63] } \\
\text { 2) Second hit sCD40L [64] } \\
\text { 3) Second hit anti-HLA antibody [66] } \\
\text { 4) Second hit platelet microparticles [65] } \\
\text { 5) Second hit anti-HNA-3a antibody [61] } \\
\text { 6) Second hit low-IgM serum [67] }\end{array}$ & $\begin{array}{l}\text { B) No PMN influx into the alveolar airspace upon histological analysis } \\
\text { of lung tissue sections of two TRALI patients [69] }\end{array}$ \\
\hline $\begin{array}{l}\text { C) Presence of NETs: } \\
\text { 1) Presence of NETs in lungs and plasma of TRALI patients and murine } \\
\text { anti-MHC class I antibody mediated TRALI model [49] } \\
\text { 2) Presence of NET biomarkers in serum of TRALI patients as well as in } \\
\text { the lungs of mice undergoing anti-MHC class I mediated TRALI [62] }\end{array}$ & $\begin{array}{l}\text { C) Occurrence of TRALI after PMN depletion in anti-HNA-3a mediated } \\
\text { TRALI mouse model (despite decreased disease severity) [53] }\end{array}$ \\
\hline $\begin{array}{l}\text { D) PMN interaction with von Willebrand factor via CTL-2 allowed anti- } \\
\text { HNA-3a antibody to induce signal transduction via CD11b/CD18, } \\
\text { leading to PMN-activation and agglutination [54] }\end{array}$ & $\begin{array}{l}\text { D) No dependence on PMNs (and partial independence of Fc } \mathrm{R} \text { Rs), but } \\
\text { dependence on complement component C5a in a murine model of } \\
\text { anti-MHC class I antibody-mediated TRALI [60] }\end{array}$ \\
\hline $\begin{array}{l}\text { E) Pulmonary PMN infiltration in various animal models of TRALI: } \\
\text { 1) Antibody-mediated TRALI }[11,13,47-55,57] \\
\text { 2) Non-antibody-mediated TRALI }[55,56]\end{array}$ & \\
\hline $\begin{array}{l}\text { F) Essential involvement of PMN-Fc } \gamma \text { Rs in a murine model of anti-MHC class I } \\
\text { antibody mediated TRALI [47] }\end{array}$ & \\
\hline
\end{tabular}

TRALI may have been related to the low numbers of sequestered PMNs [68]. Furthermore, another study reported two TRALI patients which did not demonstrate PMN influx into the alveolar airspace upon histological analysis of lung tissue sections [69]. Both of these patients, remarkably, were familiar with cardiovascular diseases. Because of this cardiogenic involvement it cannot be ruled out that these patients may perhaps have suffered from transfusion-related circulatory overload (TACO) instead of TRALI. Cardiac failure was recently identified as a major risk factor for TACO in a retrospective cohort study of 66 TACO patients [70]. Also another prospective study of 200 TACO patients found congestive heart failure to be one of the risk factors associated with TACO [71]. Similarly, a previous study also retrospectively identified congestive heart failure as risk factor for TACO in 98 TACO cases [72]. TRALI is non-cardiogenic in contrast to TACO, despite a similar clinical presentation, and their underlying pathogenesis may also be different. But this will need to be further investigated.

Despite a similar clinical presentation of ARDS and TRALI with evidence for an important pathogenic involvement of PMNs in both disorders, the pathogeneses of ARDS and TRALI appear fundamentally different, which is important for the efficacy of potential future therapies. TRALI, unlike ARDS, does not have any temporally associated risk factors for acute lung injury (such as pneu- monia, sepsis, aspiration, multiple trauma). The differing pathogenesis is for instance supported by the fact that plasma IL-10 levels were found to be low in murine models of TRALI [13] as well as in human TRALI patients [14], while the IL-10 levels were found to be increased in sepsis-related acute lung injury [14]. Also other studies have found IL-10 levels to be increased in ARDS [73]. Additionally, a deficiency of CD4+ CD25+ FoxP3+ T regulatory cells has been suggested to be a first-hit risk factor for TRALI, using a murine model of antibody-mediated TRALI [13]. In contrast, alveolar CD4+ CD25+ FoxP3+ T regulatory cells were reported to be increased in ARDS patients, with a concomitant correlation with increased IL-10 levels [74]. It will be important to more firmly establish the role T regulatory cells and IL-10 in both ARDS and TRALI. Overall, more research is required to shed light on the pathogenesis of both ARDS and TRALI, including the involvement of PMNs in the development of both diseases, which may open up potential new therapeutic approaches.

\section{Disclosure Statement}

The authors declare no competing financial interests. 


\section{References}

1 Ashbaugh DG, Bigelow DB, Petty TL, Levine BE: Acute respiratory distress in adults. Lancet 1967;2:319-323.

2 Ranieri VM, Rubenfeld GD, Thompson BT, et al: Acute respiratory distress syndrome: the Berlin Definition. JAMA 2012;307:2526-2533.

3 Laffey JG, Misak C, Kavanagh BP: Acute respiratory distress syndrome. BMJ 2017;359:j5055.

4 Bellani G, Laffey JG, Pham T, et al: Epidemiology, patterns of care, and mortality for patients with acute respiratory distress syndrome in intensive care units in 50 countries. JAMA 2016;315:788-800.

5 Fatalities Reported to FDA Following Blood Collection and Transfusions: Annual Summary for Fiscal Year 2015. Washington, DC: US Department of Health and Human Services, Office of the Assistant Secretary of Health, 2016.

6 Kleinman S, Caulfield T, Chan P, et al: Toward an understanding of transfusion-related acute lung injury: statement of a consensus panel. Transfusion 2004;44: 1774-1789.

7 Semple JW, McVey MJ, Kim M, et al: Targeting transfusion-related acute lung injury: the journey from basic science to novel therapies. Crit Care Med 2018; 46:e452-e458.

8 Vlaar AP, Hofstra JJ, Determann RM, et al: Transfusion-related acute lung injury in cardiac surgery patients is characterized by pulmonary inflammation and coagulopathy: a prospective nested case-control study. Crit Care Med 2012;40:2813-2820.

9 Toy P, Gajic O, Bacchetti P, et al: Transfusion-related acute lung injury: incidence and risk factors. Blood 2012;119:1757-1767.

10 Roubinian NH, Looney MR, Kor DJ, et al: Cytokines and clinical predictors in distinguishing pulmonary transfusion reactions. Transfusion 2015;55:1838-1846.

11 Kapur R, Kim M, Shanmugabhavananthan S, et al: Creactive protein enhances murine antibody-mediated transfusion-related acute lung injury. Blood 2015;126: 2747-2751.

12 Kapur R, Kim M, Rondina MT, Porcelijn L, Semple JW: Elevation of C-reactive protein levels in patients with transfusion-related acute lung injury. Oncotarget 2016;7:78048-78054.

13 Kapur R, Kim M, Aslam R, et al: T regulatory cells and dendritic cells protect against transfusion-related acute lung injury via IL-10. Blood 2017;129:2557-2569.

14 Kapur R, Kim M, Rebetz J, Rondina MT, Porcelijn L, Semple JW: Low levels of interleukin-10 in patients with transfusion-related acute lung injury. Ann Translat Med 2017;5:339.

15 Peters AM: Just how big is the pulmonary granulocyte pool? Clin Sci (Lond) 1998;94:7-19.

16 Ussov WY, Peters AM, Savill J, et al: Relationship between granulocyte activation, pulmonary granulocyte kinetics and alveolar permeability in extrapulmonary inflammatory disease. Clin Sci (Lond) 1996;91:329-335.

17 Sadik CD, Luster AD: Lipid-cytokine-chemokine cascades orchestrate leukocyte recruitment in inflammation. J Leukoc Biol 2012;91:207-215.

- 18 Mocsai A, Walzog B, Lowell CA: Intracellular signalling during neutrophil recruitment. Cardiovasc Res 2015; 107:373-385.

19 Kolaczkowska E, Kubes P: Neutrophil recruitment and function in health and inflammation. Nat Rev Immunol 2013;13:159-175.

20 Norman KE, Moore KL, McEver RP, Ley K: Leukocyte rolling in vivo is mediated by $\mathrm{P}$-selectin glycoprotein ligand-1. Blood 1995;86:4417-4421.

21 Hirata T, Merrill-Skoloff G, Aab M, et al: P-Selectin glycoprotein ligand 1 (PSGL-1) is a physiological ligand for E-selectin in mediating $\mathrm{T}$ helper 1 lymphocyte migration. J Exp Med 2000;192:1669-1676.
2 Sperandio M, Smith ML, Forlow SB, et al: P-selectin glycoprotein ligand-1 mediates L-selectin-dependent leukocyte rolling in venules. J Exp Med 2003;197: 1355-1363.

23 Wang L, Fuster M, Sriramarao P, Esko JD: Endothelial heparan sulfate deficiency impairs L-selectin- and chemokine-mediated neutrophil trafficking during inflammatory responses. Nat Immunol 2005;6:902-910.

24 Heit B, Tavener S, Raharjo E, Kubes P: An intracellular signaling hierarchy determines direction of migration in opposing chemotactic gradients. J Cell Biol 2002; 159:91-102.

25 Pruenster M, Kurz AR, Chung KJ, et al: Extracellular MRP8/14 is a regulator of beta2 integrin-dependent neutrophil slow rolling and adhesion. Nat Commun 2015;6:6915.

26 Wang Q, Doerschuk CM: Neutrophil-induced changes in the biomechanical properties of endothelial cells: roles of ICAM-1 and reactive oxygen species. J Immunol 2000;164:6487-6494.

27 Phillipson M, Heit B, Colarusso P, et al: Intraluminal crawling of neutrophils to emigration sites: a molecularly distinct process from adhesion in the recruitment cascade. J Exp Med 2006;203:2569-2575.

28 Phillipson M, Heit B, Parsons SA, et al: Vavl is essential for mechanotactic crawling and migration of neutrophils out of the inflamed microvasculature. J Immunol 2009; 182:6870-6878

29 Hind LE, Vincent WJ, Huttenlocher A: Leading from the back: the role of the uropod in neutrophil polarization and migration. Dev Cell 2016;38:161-169

30 Zimmerman GA, Albertine KH, Carveth HJ, et al: En dothelial activation in ARDS. Chest 1999;116(1 suppl): 18S-24S.

31 Morsing KSH, Peters AL, van Buul JD, Vlaar APJ: The role of endothelium in the onset of antibody-mediated TRALI. Blood Rev 2018;32:1-7.

32 Flannagan RS, Jaumouille V, Grinstein S: The cell biology of phagocytosis. Annu Rev Pathol 2012;7:61-98.

33 Gordon S. Phagocytosis: an immunobiologic process. Immunity 2016;44:463-475.

34 Borregaard N: Neutrophils, from marrow to microbes. Immunity 2010;33:657-670.

35 Kapur R, Einarsdottir HK, Vidarsson G: IgG-effector functions: 'the good, the bad and the ugly'. Immunol Lett 2014;160:139-144.

36 Vidarsson G, van de Winkel JG: Fc receptor and complement receptor-mediated phagocytosis in host defence. Curr Opin Infect Dis 1998;11:271-278.

37 Hogarth PM, Pietersz GA: Fc receptor-targeted therapies for the treatment of inflammation, cancer and beyond. Nat Rev Drug Discov 2012;11:311-331.

38 Sengelov H: Complement receptors in neutrophils. Crit Rev Immunol 1995;15:107-131.

39 Barlic J, Andrews JD, Kelvin AA, et al: Regulation of tyrosine kinase activation and granule release through beta-arrestin by CXCRI. Nat Immunol 2000;1:227-233.

40 Brinkmann V, Reichard U, Goosmann C, et al: Neutrophil extracellular traps kill bacteria. Science 2004; 303:1532-1535.

41 Wong SL, Demers M, Martinod K, et al: Diabetes primes neutrophils to undergo NETosis, which impairs wound healing. Nat Med 2015;21:815-819.

42 Yildiz C, Palaniyar N, Otulakowski G, et al: Mechanical ventilation induces neutrophil extracellular trap formation. Anesthesiology 2015;122:864-875.

43 Kallenberg CG, Heeringa P, Stegeman CA: Mechanisms of disease: pathogenesis and treatment of ANCA-associated vasculitides. Nat Clin Pract Rheumatol 2006;2:661-670.

44 Jonsson F, Mancardi DA, Kita Y, et al: Mouse and human neutrophils induce anaphylaxis. J Clin Invest 2011;121:1484-1496.
5 Xu X, Zhang D, Zhang H, et al: Neutrophil histamine contributes to inflammation in mycoplasma pneumonia. J Exp Med 2006;203:2907-2917.

46 Sandborn WJ, Targan SR: Biologic therapy of inflammatory bowel disease. Gastroenterology 2002;122: 1592-1608.

47 Looney MR, Su X, Van Ziffle JA, Lowell CA, Matthay MA: Neutrophils and their Fc gamma receptors are essential in a mouse model of transfusion-related acute lung injury. J Clin Invest 2006;116:1615-1623.

48 Looney MR, Nguyen JX, Hu Y, et al: Platelet depletion and aspirin treatment protect mice in a two-event model of transfusion-related acute lung injury. J Clin Invest 2009;119:3450-3461.

49 Caudrillier A, Kessenbrock K, Gilliss BM, et al: Platelets induce neutrophil extracellular traps in transfusion-related acute lung injury. J Clin Invest 2012;122: 2661-2671.

50 Fung YL, Kim M, Tabuchi A, et al: Recipient T lymphocytes modulate the severity of antibody-mediated transfusion-related acute lung injury. Blood 2010;116: 3073-3079.

51 Semple JW, Kim M, Hou J, et al: Intravenous immunoglobulin prevents murine antibody-mediated acute lung injury at the level of neutrophil reactive oxygen species (ROS) production. PLoS One 2012;7:e31357.

52 McKenzie CG, Kim M, Singh TK, et al: Peripheral blood monocyte-derived chemokine blockade prevents murine transfusion-related acute lung injury (TRALI). Blood 2014;123:3496-3503.

53 Bayat B, Tjahjono Y, Sydykov A, et al: Anti-human neutrophil antigen-3a induced transfusion-related acute lung injury in mice by direct disturbance of lung endothelial cells. Arterioscler Thromb Vasc Biol 2013; 33:2538-2548.

54 Bayat B, Tjahjono Y, Berghofer H, et al: Choline transporter-like protein-2: new von Willebrand Factor-binding partner involved in antibody-mediated neutrophil activation and transfusion-related acute lung injury. Arterioscler Thromb Vasc Biol 2015;35:1616-1622.

55 Kelher MR, Masuno T, Moore EE, et al: Plasma from stored packed red blood cells and MHC class I antibodies causes acute lung injury in a 2 -event in vivo rat model. Blood 2009;113:2079-2087.

56 Tung JP, Fung YL, Nataatmadja M, et al: A novel in vivo ovine model of transfusion-related acute lung injury (TRALI). Vox Sang 2011;100:219-230.

57 Kapur R, Kim M, Rebetz J, et al: Gastrointestinal microbiota contributes to the development of murine transfusion-related acute lung injury. Blood Adv 2018; 2:1651-1663.

58 Dry SM, Bechard KM, Milford EL, Churchill WH, Benjamin RJ: The pathology of transfusion-related acute lung injury. Am J Clin Pathol 1999;112:216-221.

59 Silliman CC, Ambruso DR, Boshkov LK: Transfusionrelated acute lung injury. Blood 2005;105:2266-2273.

60 Strait RT, Hicks W, Barasa N, et al: MHC class I-specific antibody binding to nonhematopoietic cells drives complement activation to induce transfusion-related acute lung injury in mice. J Exp Med 2011;208:2525-2544.

61 Silliman CC, Curtis BR, Kopko PM, et al: Donor antibodies to HNA-3a implicated in TRALI reactions prime neutrophils and cause PMN-mediated damage to human pulmonary microvascular endothelial cells in a two-event in vitro model. Blood 2007;109:1752-1755.

62 Thomas GM, Carbo C, Curtis BR, et al: Extracellular DNA traps are associated with the pathogenesis of TRALI in humans and mice. Blood 2012;119:6335-6343.

63 Wyman TH, Bjornsen AJ, Elzi DJ, et al: A two-insult in vitro model of PMN-mediated pulmonary endothelial damage: requirements for adherence and chemokine release. Am J Physiol Cell Physiol 2002;283:C1592-C1603. 
64 Khan SY, Kelher MR, Heal JM, et al: Soluble CD40 ligand accumulates in stored blood components, primes neutrophils through CD40, and is a potential cofactor in the development of transfusion-related acute lung injury. Blood 2006; 108:2455-2462.

65 Xie RF, Hu P, Wang ZC, et al: Platelet-derived microparticles induce polymorphonuclear leukocyte-mediated damage of human pulmonary microvascular endothelial cells. Transfusion 2015;55:1051-1057.

66 Khoy K, Nguyen MVC, Masson D, et al: Transfusionrelated acute lung injury: critical neutrophil activation by anti-HLA-A2 antibodies for endothelial permeability. Transfusion 2017;57:1699-1708.

-67 Nishimura M, Takanashi M, Okazaki H, Satake M: Lung microvascular endothelial cell injury caused by treatment with polymorphonuclear neutrophils and low-IgM serum: a model of transfusion-related acute lung injury. Lung 2006;184:25-32.

68 Finlayson J, Grey D, Kavanagh L, Witt C: Transfusionrelated acute lung injury in a neutropenic patient. Intern Med J 2011;41:638-641.

69 Danielson C, Benjamin RJ, Mangano MM, Mills CJ, Waxman DA: Pulmonary pathology of rapidly fatal transfusion-related acute lung injury reveals minimal evidence of diffuse alveolar damage or alveolar granulocyte infiltration. Transfusion 2008;48:2401-2408.

70 Bosboom JJ, Klanderman RB, Zijp M, et al: Incidence, risk factors, and outcome of transfusion-associated circulatory overload in a mixed intensive care unit population: a nested case-control study. Transfusion 2018; 58:498-506.

71 Roubinian NH, Hendrickson JE, Triulzi DJ, et al: Contemporary risk factors and outcomes of transfusionassociated circulatory overload. Crit Care Med 2018; 46:577-585.

72 Lieberman L, Maskens C, Cserti-Gazdewich C, et al: A retrospective review of patient factors, transfusion practices, and outcomes in patients with transfusionassociated circulatory overload. Transfus Med Rev 2013;27:206-212.

73 Aisiku IP, Yamal JM, Doshi P, et al: Plasma cytokines IL-6, IL-8, and IL-10 are associated with the development of acute respiratory distress syndrome in patient with severe traumatic brain injury. Crit Care 2016;20: 288.

74 Adamzik M, Broll J, Steinmann J, et al: An increased alveolar CD4 + CD25 + Foxp3 + T-regulatory cell ratio in acute respiratory distress syndrome is associated with increased 30-day mortality. Intensive Care Med 2013;39:1743-1751.

75 Bachofen M, Weibel ER: Alterations of the gas exchange apparatus in adult respiratory insufficiency associated with septicemia. Am Rev Respir Dis 1977;116: 589-615.

76 Elliott CG, Zimmerman GA, Orme JF Jr, Morris AH, Mortensen JD: Granulocyte aggregation in adult respiratory distress syndrome (ARDS) - serial histologic and physiologic observations. Am J Med Sci 1985;289: 70-74.

77 Pratt PC, Vollmer RT, Shelburne JD, Crapo JD: Pulmonary morphology in a multihospital collaborative extracorporeal membrane oxygenation project. I. Light microscopy. Am J Pathol 1979;95:191-214.

78 Ognibene FP, Martin SE, Parker MM, et al: Adult respiratory distress syndrome in patients with severe neutropenia. N Engl J Med 1986;315:547-551.

79 Maunder RJ, Hackman RC, Riff E, Albert RK, Springmeyer SC: Occurrence of the adult respiratory distress syndrome in neutropenic patients. Am Rev Respir Dis 1986;133:313-316.

80 Sivan Y, Mor C, al-Jundi S, Newth CJ: Adult respiratory distress syndrome in severely neutropenic children. Pediatr Pulmonol 1990;8:104-108.
Braude S, Apperley J, Krausz T, Goldman JM, Royston D: Adult respiratory distress syndrome after allogeneic bone-marrow transplantation: evidence for a neutrophil-independent mechanism. Lancet 1985;1:12391242 .

82 Mokart D, Guery BP, Bouabdallah R, et al: Deactivation of alveolar macrophages in septic neutropenic ARDS. Chest 2003;124:644-652.

83 Mokart D, Kipnis E, Guerre-Berthelot P, et al: Monocyte deactivation in neutropenic acute respiratory distress syndrome patients treated with granulocyte colony-stimulating factor. Crit Care 2008;12:R17.

84 Vansteenkiste JF, Boogaerts MA: Adult respiratory distress syndrome in neutropenic leukemia patients. Blut 1989;58:287-290.

85 McWhinney PH, Gillespie SH, Kibbler CC, Hoffbrand AV, Prentice HG: Streptococcus mitis and ARDS in neutropenic patients. Lancet 1991;337:429.

86 Laufe MD, Simon RH, Flint A, Keller JB: Adult respir atory distress syndrome in neutropenic patients. Am J Med 1986;80:1022-1026.

87 Geerts L, Jorens PG, Willems J, De LM, Slegers H: Natural inhibitors of neutrophil function in acute respiratory distress syndrome. Crit Care Med 2001;29: 1920-1924.

88 Summers C, Singh NR, White JF, et al: Pulmonary retention of primed neutrophils: a novel protective host response, which is impaired in the acute respiratory distress syndrome. Thorax 2014;69:623-629.

89 Weiland JE, Davis WB, Holter JF, et al: Lung neutrophils in the adult respiratory distress syndrome. Clinical and pathophysiologic significance. Am Rev Respir Dis 1986;133:218-225.

90 Hallgren R, Borg T, Venge P, Modig J. Signs of neutrophil and eosinophil activation in adult respiratory distress syndrome. Crit Care Med 1984;12:14-18.

91 Cohen AB, MacArthur C, Idell S, et al: A peptide from alveolar macrophages that releases neutrophil enzymes into the lungs in patients with the adult respiratory distress syndrome. Am Rev Respir Dis 1988;137:11511158.

92 Wittkowski H, Sturrock A, van Zoelen MA, et al: Neutrophil-derived S100A12 in acute lung injury and respiratory distress syndrome. Crit Care Med 2007;35: 1369-1375.

93 Kangelaris KN, Prakash A, Liu KD, et al: Increased expression of neutrophil-related genes in patients with early sepsis-induced ARDS. Am J Physiol Lung Cell Mol Physiol 2015;308:L1102-L1113.

94 Rivkind AI, Siegel JH, Littleton M, et al: Neutrophil oxidative burst activation and the pattern of respiratory physiologic abnormalities in the fulminant posttraumatic adult respiratory distress syndrome. Circ Shock 1991;33:48-62.

95 Fowler AA, Fisher BJ, Centor RM, Carchman RA: Development of the adult respiratory distress syndrome: progressive alteration of neutrophil chemotactic and secretory processes. Am J Pathol 1984;116:427-435.

96 Zimmerman GA, Renzetti AD, Hill HR: Granulocyte adherence in pulmonary and systemic arterial blood samples from patients with adult respiratory distress syndrome. Am Rev Respir Dis 1984;129:798-804.

97 Groeneveld AB, Raijmakers PG, Hack CE, Thijs LG: Interleukin 8-related neutrophil elastase and the severity of the adult respiratory distress syndrome. Cytokine 1995;7:746-752.

98 Lin CC, Lin CY: Enhanced chemiluminescence with decreased antibody-dependent cellular cytotoxicity of human alveolar neutrophil in patients with adult respiratory distress syndrome. Respiration 1992;59:265-271.

99 Wewers MD, Herzyk DJ, Gadek JE: Alveolar fluid neutrophil elastase activity in the adult respiratory distress syndrome is complexed to alpha-2-macroglobulin. J Clin Invest 1988;82:1260-1267.
100 Chollet-Martin S, Montravers P, Gibert C, et al: Subpopulation of hyperresponsive polymorphonuclear neutrophils in patients with adult respiratory distress syndrome. Role of cytokine production. Am Rev Respir Dis 1992;146:990-996.

101 Matute-Bello G, Liles WC, Radella F, et al: Neutrophil apoptosis in the acute respiratory distress syndrome. Am J Respir Crit Care Med 1997;156:1969-1977.

102 Matute-Bello G, Liles WC, Radella F, et al: Modulation of neutrophil apoptosis by granulocyte colony-stimulating factor and granulocyte/macrophage colonystimulating factor during the course of acute respiratory distress syndrome. Crit Care Med 2000;28:1-7.

103 Fialkow L, Fochesatto FL, Bozzetti MC, et al: Neutrophil apoptosis: a marker of disease severity in sepsis and sepsis-induced acute respiratory distress syndrome. Crit Care 2006;10:R155.

104 Fletcher MP, Vassar MJ, Holcroft JW: Patients with adult respiratory distress syndrome (ARDS) demonstrate in vivo neutrophil activation associated with diminished binding of neutrophil-specific monoclonal antibody 31D8. Inflammation 1988;12:455-473.

105 Warshawski FJ, Sibbald WJ, Driedger AA, Cheung H: Abnormal neutrophil-pulmonary interaction in the adult respiratory distress syndrome. Qualitative and quantitative assessment of pulmonary neutrophil kinetics in humans with in vivo 111indium neutrophil scintigraphy. Am Rev Respir Dis 1986;133:797-804.

106 Zimmerman GA, Renzetti AD, Hill HR: Functiona and metabolic activity of granulocytes from patients with adult respiratory distress syndrome. Evidence for activated neutrophils in the pulmonary circulation. Am Rev Respir Dis 1983;127:290-300.

107 Martin TR, Pistorese BP, Hudson LD, Maunder RJ: The function of lung and blood neutrophils in patients with the adult respiratory distress syndrome. Implications for the pathogenesis of lung infections. Am Rev Respir Dis 1991;144:254-262.

108 Powe JE, Short A, Sibbald WJ, Driedger AA: Pulmonary accumulation of polymorphonuclear leukocytes in the adult respiratory distress syndrome. Crit Care Med 1982;10:712-718.

109 Idell S, Kucich U, Fein A, et al: Neutrophil elastase-releasing factors in bronchoalveolar lavage from patients with adult respiratory distress syndrome. Am Rev Respir Dis 1985;132:1098-1105.

110 Mascellino MT, Delogu G, Pelaia MR, et al: Reduced bactericidal activity against Staphylococcus aureus and Pseudomonas aeruginosa of blood neutrophils from patients with early adult respiratory distress syndrome. J Med Microbiol 2001;50:49-54.

111 Li H, Zhou X, Tan H, et al: Neutrophil extracellular traps contribute to the pathogenesis of acid-aspirationinduced ALI/ARDS. Oncotarget 2018;9:1772-1784.

112 Lefrancais E, Mallavia B, Zhuo H, Calfee CS, Looney MR: Maladaptive role of neutrophil extracellular traps in pathogen-induced lung injury. JCI Insight 2018; 3:doi: 10.1172/jci.insight.98178.

113 Aggarwal A, Baker CS, Evans TW, Haslam PL: G-CSF and IL-8 but not GM-CSF correlate with severity of pulmonary neutrophilia in acute respiratory distress syndrome. Eur Respir J 2000;15:895-901.

114 Steinberg KP, Milberg JA, Martin TR, et al: Evolution of bronchoalveolar cell populations in the adult respiratory distress syndrome. Am J Respir Crit Care Med 1994;150:113-122.

115 Diaz J, Tornel PL, Jara P, et al: The value of polymorphonuclear elastase in adult respiratory distress syndrome. Clin Chim Acta 1995;236:119-127.

116 Guervilly C, Lacroix R, Forel JM, et al: High levels of circulating leukocyte microparticles are associated with better outcome in acute respiratory distress syndrome. Crit Care 2011;15:R31. 
117 Fowler AA, Hyers TM, Fisher BJ, et al: The adult respiratory distress syndrome. Cell populations and soluble mediators in the air spaces of patients at high risk. Am Rev Respir Dis 1987;136:1225-1231.

118 Nakos G, Kitsiouli EI, Tsangaris I, Lekka ME: Bronchoalveolar lavage fluid characteristics of early intermediate and late phases of ARDS. Alterations in leukocytes, proteins, PAF and surfactant components. Intensive Care Med 1998;24:296-303.

119 Nelson S, Belknap SM, Carlson RW, et al: A randomized controlled trial of filgrastim as an adjunct to antibiotics for treatment of hospitalized patients with community-acquired pneumonia. CAP Study Group. J Infect Dis 1998;178:1075-1080.

120 Metnitz PG, Bartens C, Fischer M, et al: Antioxidant status in patients with acute respiratory distress syndrome. Intensive Care Med 1999;25:180-185.

121 Yokoi K, Mukaida N, Harada A, Watanabe Y, Matsushima K: Prevention of endotoxemia-induced acute respiratory distress syndrome-like lung injury in rabbits by a monoclonal antibody to IL-8. Lab Invest 1997; $76: 375-384$
122 Germann PG, Hafner D: A rat model of acute respiratory distress syndrome (ARDS): Part 1. Time dependency of histological and pathological changes. J Pharmacol Toxicol Methods 1998;40:101-107.

123 Sercundes MK, Ortolan LS, Debone D, et al: Targeting neutrophils to prevent malaria-associated acute lung injury/acute respiratory distress syndrome in mice. PLoS Pathog 2016;12:e1006054.

124 Modig J, Samuelsson T: Prevention by granulocyte depletion of endotoxin-induced adult respiratory distress syndrome. An experimental study in pigs. Resuscitation 1987;15:187-199.

125 Deng G, Bi J, Kong F, et al: Acute respiratory distress syndrome induced by H9N2 virus in mice. Arch Virol 2010;155:187-195.

126 Goldman G, Welbourn R, Kobzik L, et al: Reactive oxygen species and elastase mediate lung permeability after acid aspiration. J Appl Physiol 1992;73:571-575.

27 Inagawa R, Okada H, Takemura G, et al: Ultrastructural alteration of pulmonary capillary endothelial glycocalyx during endotoxemia. Chest. 2018;154:317-325.
128 Hangen DH, Segall GM, Harney EW, et al: Kinetics of leukocyte sequestration in the lungs of acutely septic primates: a study using 111In-labeled autologous leukocytes. J Surg Res 1990;48:196-203.

129 Stokke T, Burchardi H, Hensel I, Horl WH: Experimental studies on the adult respiratory distress syndrome: effects of induced DIC; granulocytes and elastase in mini pigs. Eur J Clin Invest 1985;15:415-421.

130 Holman RG, Maier RV: Superoxide production by neutrophils in a model of adult respiratory distress syndrome. Arch Surg 1988;123:1491-1495.

131 McCord JM, Gao B, Leff J, Flores SC: Neutrophil-generated free radicals: possible mechanisms of injury in adult respiratory distress syndrome. Environ Health Perspect 1994;102(suppl 10):57-60.

132 Narasaraju T, Yang E, Samy RP, et al: Excessive neutrophils and neutrophil extracellular traps contribute to acute lung injury of influenza pneumonitis. Am J Pathol 2011;179:199-210. 